This document is confidential and is proprietary to the American Chemical Society and its authors. Do not copy or disclose without written permission. If you have received this item in error, notify the sender and delete all copies.

\title{
Mycosporine-like amino acids and other phytochemicals directly detected by high-resolution NMR on Klamath (Aphanizomenon flos-aquae) blue-green algae
}

\begin{tabular}{|r|l|}
\hline Journal: & Journal of Agricultural and Food Chemistry \\
\hline Manuscript ID & jf-2016-02615w.R1 \\
\hline Manuscript Type: & Article \\
\hline Complete List of Authors: & $\begin{array}{l}\text { Righi, Valeria; Università di Bologna, Dipartimento di Scienze per la Qualità } \\
\text { della Vita } \\
\text { Parenti, Francesca; Università di Modena e Reggio Emilia, Dipartimento di } \\
\text { scienze Chimiche e Geologiche } \\
\text { Schenetti, Luisa; Universita di Modena e Reggio Emilia, Dipartimento di } \\
\text { Scienze della Vita } \\
\text { Mucci, Adele; Università di Modena e Reggio Emilia, Dipartimento di } \\
\text { Scienze Chimiche e Geologiche }\end{array}$ \\
\hline
\end{tabular}



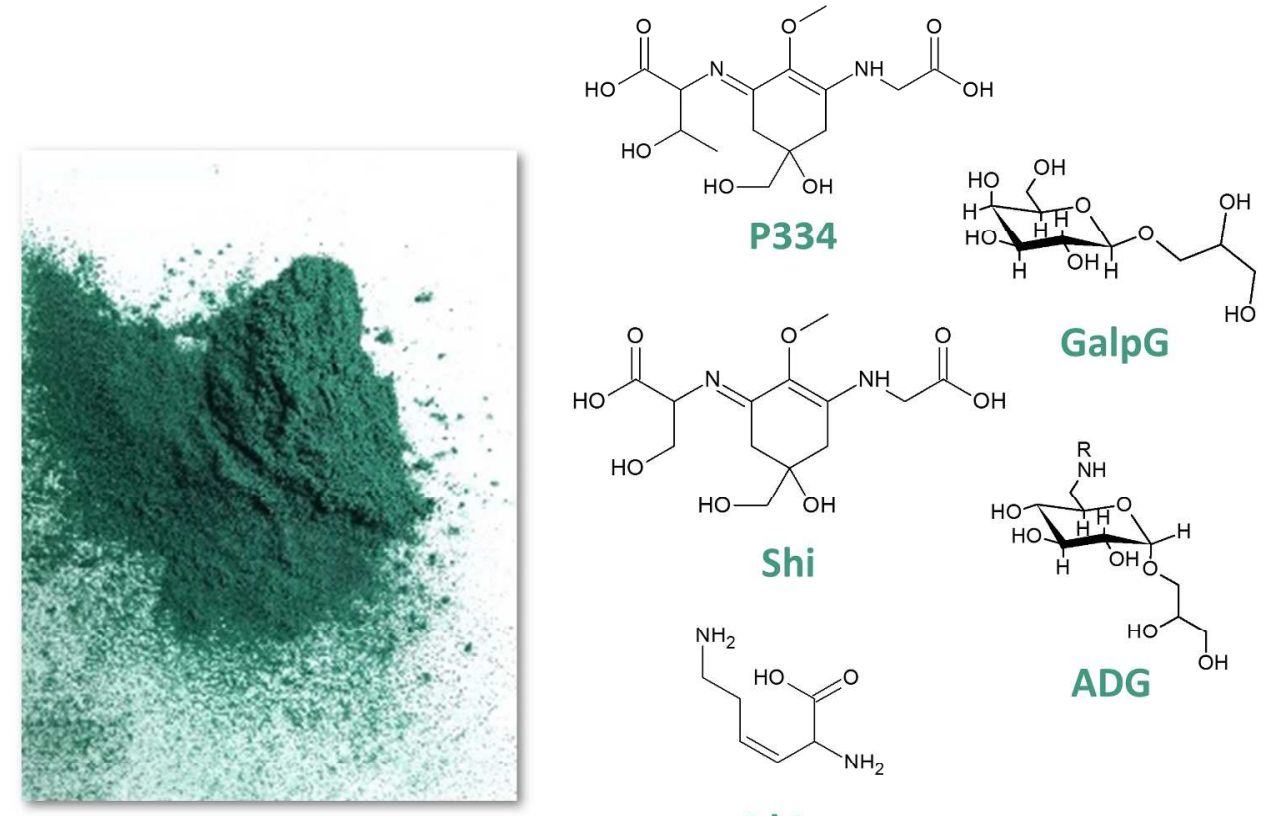

\section{GalpG}

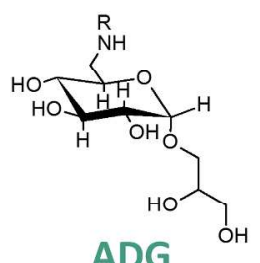

Dhlys

For Table of Contents only

$700 \times 500 \mathrm{~mm}(96 \times 96 \mathrm{DPI})$ 


\section{Mycosporine-like amino acids and other phytochemicals directly}

2 detected by high-resolution NMR on Klamath (Aphanizomenon flos-

3 aquae) blue-green algae

4 Valeria Righi, ${ }^{\mathrm{a}}$ Francesca Parenti, ${ }^{\mathrm{b}}$ Luisa Schenetti, ${ }^{\mathrm{c}}$ Adele Mucci ${ }^{\mathrm{b} *}$

$5 \quad{ }^{a}$ Dipartimento di Scienze per la Qualità della Vita, Università di Bologna, via Corso d'Augusto 237, 47921

6 Rimini, Italy

7 b Dipartimento di Scienze Chimiche e Geologiche, Università di Modena e Reggio Emilia, Via G. Campi 103,

841125 Modena, Italy

9 cDipartimento di Scienze della Vita, Università di Modena e Reggio Emilia, Via G. Campi 103, 41125

10 Modena, Italy

11

12

13 Corresponding author:

14 Prof. Adele Mucci

15 Dipartimento di Scienze Chimiche e Geologiche

16 Università di Modena e Reggio Emilia

17 Via G. Campi 103

$18 \quad 41125$ Modena

19 Italy

20

Tel.: +39 059 2058636; e-mail address: adele.mucci@unimore.it 
23

24

25

26

27

\section{Abstract}

This study describes for the first time the use of the high-resolution nuclear magnetic resonance (NMR) on Klamath (Aphanizomenon flos-aquae) blue-green algae directly on powder suspension. These algae are considered a "superfood", due to their complete nutritional profile that has proved to have important therapeutic effects. The main advantage of NMR spectroscopy is that it permits the detection of a number of metabolites all at once. Klamath algae metabolome revealed to be quite complex, and the most peculiar phytochemicals that can be detected directly on algae by NMR are mycosporine-like amino acids, (porphyra-334, P334; shinorine, Shi) and low molecular weight glycosides (glyceryl $\beta$-D-galactopyranoside, GalpG; glyceryl 6-amino-6-deoxy- $\alpha$-D-glucopyranoside, ADG) all compounds with a high nutraceutical value. It is also noteworthy the presence of cis-3,4-DhLys that was revealed for the first time. This molecule could be involved in the anticancer properties ascribed to AFA.

(3)

\section{5}

K6

Keywords: Aphanizomenon flos-aquae, Nuclear Magnetic Resonance spectroscopy, Klamath algae, mycosporine-like amino acids, glycosides, ESI-QTOF mass spectrometry 


\section{INTRODUCTION}

Aphanizomenon flos-aquae (AFA) is a wild freshwater unicellular microalga that spontaneously grows in copious amounts in Upper Klamath Lake (Klamath Falls, OR, USA) a volcanic lake with hot, deep and mineral rich waters. The combination of water properties, clean air, and high intensity sunlight make the unique ecosystem of Upper Klamath Lake the most perfect growing environment for this algae. AFA from Klamath Lake attracts the interest of several scientists owing to its complete nutritional profile and therapeutic properties and it is consumed as a nutrient food source and for its health-enhancing properties. ${ }^{1-5}$ The microalga AFA Klamath exerts beneficial effects on various neurological dysfunctions, including neurodegenerative diseases such as Alzheimer's and Parkinson's, multiple sclerosis, hyperactivity and attention deficit disorders, autism, depression, memory deficit and mood disturbances. ${ }^{16-12}$

AFA algae are prokaryote cells (cyanobacteria) which are capable to implement the photosynthesis process despite their simple structure. Their geen-blue colour is due to the presence of phycobiliproteins, a family of highly soluble and reasonably stable fluorescent proteins containing a covalently linked tetrapyrrole prosthetic group (phycocyanobiline). Phycocyanobilines are pigments that collect light and convey it (through fluorescence resonance energy transfer) to a pair of chlorophyll molecules located in the photosynthetic reaction center of the cyanobacteria starting the photosynthetic process. AFA is an important source of the blue photosynthetic pigment phycocyanin, (a complex between the pigment phycocyanobiline with phycobiliproteins) which has been described as a strong antioxidant ${ }^{13-15}$ and anti-inflammatory ${ }^{16,17}$ natural compound, as evidenced by in vitro and in vivo studies on phycocyanin from the cyanophyta Spirulina platensis. In addition, Klamath is an important source of $\beta$-phenylethylamine, a sort of natural endogenous amphetamine-like compound that is able to modulate mood.

Recently, attention has also been devoted to the composition of AFA which appear to contain mycosporine-like amino acids (MAAs), in particular porphyra-334 (P334) and shinorine (Shi), as monoamine oxidase (MAO) inhibitors, which seem present in relatively high concentration in AFA Klamath microalgae..$^{5,18,19}$ These are structurally simple water-soluble molecules, with a molecular weight of 300-350 $\mathrm{Da}$, that easily cross the blood-brain barrier, and then are able to express their MAO-B inhibitory potential in the area where it is mostly needed, the brain. Moreover, MAA are reported to be antioxidant, UV-protective and wound healing agents. ${ }^{20}$ 
For the chemical analysis of these biologically active compounds, different conventional techniques

71

72

73

are used: extraction, chromatography, ${ }^{21-23}$ and UV-Vis and IR. ${ }^{24,25}$ Each of these chemical analysis techniques allows identifying only one or few classes of chemical compounds at a time, and requires a sample pretreatment.

In this work, we present, for the first time to the best of our knowledge, the application of highresolution nuclear magnetic resonance (NMR) spectroscopy to the study of deuterated water $\left(\mathrm{D}_{2} \mathrm{O}\right)$ suspension of commercially available Klamath powder for the detection of several metabolites all at once. This approach has the advantage of avoiding any sample pretreatment that can alter algae composition. The NMR spectra obtained are very complex, and this work does not expect to be exhaustive in describing the metabolome of AFA but, despite the evident spectral overcrowding, we will show that P334, and at a minor extent Shi can be detected directly on the water suspension, without the need of extraction. Together with these MAAs, another two molecules were recognised, glyceryl $\beta$-D-galactopyranoside (GalpG) and cis-3,4dehydrolysine (DhLys) among other minor species. These findings were checked with Electrospray Ionization Quadrupole-Time-of-Flight mass spectrometry (ESI-QTOF-MS) and low-energy CollisionInduced Dissociation tandem mass spectrometry (CID MS/MS).

Scheme 1 near here

\section{MATERIALS AND METHODS}

Sample preparation. A suspension of dry powder of alga klamath (Farmalabor S.r.l, Canosa di Puglia, Italy, batch: P1001594-000), $40 \mathrm{mg}$ in $700 \mu \mathrm{L} \mathrm{D}_{2} \mathrm{O} 99.8 \%$, was sonicated at $25{ }^{\circ} \mathrm{C}$ for $1 \mathrm{~h}$ and directly used for NMR measurements. Samples for ESI-QTOF-MS measurements were obtained by suspending algae in deionized water $(1 \mathrm{mg}$ in $1 \mathrm{~mL})$, sonicated at $25{ }^{\circ} \mathrm{C}$ for $1 \mathrm{~h}$, centrifuged at $13000 \mathrm{rpm}$, for $10 \mathrm{~min}$ and the surnatants, diluted 1:30 in deionized water, were directly analysed. All measurements were performed at autogenous $\mathrm{pH}(5.6)$.

NMR experiments. NMR spectra were recorded with a AVANCE III HD 600 spectrometer (Bruker) equipped with a CryoProbe BBO H\&F $5 \mathrm{~mm}$ (operating at 600.13 and $150.90 \mathrm{MHz}$ for proton and carbon, respectively) at $300 \mathrm{~K}$. Ala $\mathrm{CH}_{3}$ signal (at 1.47 and $19.0 \mathrm{ppm}$, for proton and carbon, respectively, see Table S1) was used as internal reference for ${ }^{1} \mathrm{H}$ and ${ }^{13} \mathrm{C}$ chemical shifts. 1D proton spectra were acquired using the 
standard zgcppr sequence with $2.5 \mathrm{~s}$ water presaturation during relaxation delay, $12 \mathrm{kHz}$ spectral width, $64 \mathrm{k}$ data points, 64 scans. 2D COSY spectra were acquired using a standard pulse sequence (cosygpprqf) and $1 \mathrm{~s}$ water presaturation during relaxation delay, $7 \mathrm{kHz}$ spectral width, $4 \mathrm{k}$ data points, 16 scans per increment, 512 increments. 2D TOCSY spectra were acquired using a standard pulse sequence (mlevgpph19) and $0.5 \mathrm{~s}$ relaxation delay, $100 \mathrm{~ms}$ mixing (spin-lock) time, $7 \mathrm{kHz}$ spectral width, $4 \mathrm{k}$ data points, 32 scans per increment, 512 increments. 2D NOESY and ROESY spectra were acquired using standard pulse sequences (noesygpph19, roesyphpr) and $1 \mathrm{~s}$ relaxation delay, 500 and $250 \mathrm{~ms}$ mixing time, respectively, $7.2 \mathrm{kHz}$ spectral width, 4k data points, 24 scans per increment, 512 increments. 2D HSQC edited spectra were acquired using a standard pulse sequence echo-antiecho phase sensitive (hsqcedetgpsp. 3 ) and $0.5 \mathrm{~s}$ relaxation delay, $1.725 \mathrm{~ms}$ evolution time, $7 \mathrm{kHz}$ spectral width in $f_{2}$, 4k data points, 96 scans per increment, $25 \mathrm{kHz}$ spectral width in $f_{1}, 320$ increments. $2 \mathrm{D}$ HMBC spectra were acquired using a standard pulse sequence (hmbcgplpndqf) with $0.5 \mathrm{~s}$ relaxation delay, $3.4 \mathrm{~ms}$ low-pass J filter and $50 \mathrm{~ms}$ evolution time, $7 \mathrm{kHz}$ spectral width in $f_{2}, 4 \mathrm{k}$ data points, 128 scans per increment, $30 \mathrm{kHz}$ spectral width in $f_{1}, 300$ increments. HSQCTOCSY experiment was acquired using a standard pulse sequence (hsqcdiedetgpsisp.1) and $0.5 \mathrm{~s}$ relaxation delay, $1.725 \mathrm{~ms}$ evolution time, $110 \mathrm{~ms}$ spin-lock, $8 \mathrm{kHz}$ spectral width in $f_{2}$, 2k data points, 96 scans per increment, $23 \mathrm{kHz}$ spectral width in $f_{1}, 280$ increments.

ESI-QTOF experiments. Positive and negative ion high-resolution ESI-QTOF-MS and low-energy CID MS/MS spectra were acquired with an 6520 Accurate-Mass QTOF LC/MS (Agilent Technologies) coupled with a HPLC Agilent Series 1200 equipped with a Zorbax SB-C18 column, 100x2.1mm ID, $3.5 \mu \mathrm{m}$ particle size (Agilent). Eluents were acetonitrile (eluent $\mathrm{A}$ ) and $\mathrm{H}_{2} \mathrm{O}$ with $0.2 \%$ ammonium formiate (eluent B). Chromatographic runs were performed using a gradient of eluent A [starting from $1 \%$ (1 min) to $40 \%$ (in 20 $\min$ ) to $100 \%$ (in $10 \mathrm{~min}$ )]. The solvent flow rate was $0.3 \mathrm{ml} / \mathrm{min}$, the temperature kept at $25{ }^{\circ} \mathrm{C}$ and the injector volume selected was $2 \mu \mathrm{l}$. Total ion current (TIC) chromatograms were acquired in the mass range between 50 and $1700 \mathrm{~m} / \mathrm{z}$. Nitrogen was used as collision gas in MS/MS experiments. Nitrogen nebulizer pressure was $30 \mathrm{psi}$, nitrogen dry gas flow and temperature were $9 \mathrm{~L} / \mathrm{min}$ and $350{ }^{\circ} \mathrm{C}$, respectively, and capillary voltage was $3.5 \mathrm{kV}$. Exact masses were checked, in order to verify the correspondence to the proposed molecular formulas, within $10 \mathrm{ppm}$ that is the maximum estimated mass error. The isotopic peak intensity ratios of molecular species where checked with the "generate-formula-from-peaks" tool of Qualitative Analysis (Version B.04.00, Agilent Technologies, Inc. 2011). 


\section{RESULTS AND DISCUSSION}

130 Since powder alga Klamath forms suspensions in $\mathrm{D}_{2} \mathrm{O}$, we first evaluated the use of High Resolution Magic 131 Angle Spinning (HR-MAS) which is an NMR technique that bridges the divide between high-resolution

132 NMR in solution and solid-state NMR. HR-MAS is the election NMR technique when semisolid samples, 133 such as vegetable tissues, are investigated. In fact, it does not need of any pretreatment, extraction and 134 separation, and the signals from polar and apolar fractions are detected simultaneously. ${ }^{26,27}$ Nevertheless, when the NMR AFA spectra obtained with HR-MAS probe were compared to those acquired with probes for liquids (AFA suspended into standard $5 \mathrm{~mm}$ NMR tubes), we did not observe any difference (Fig. S1). Hence, we decided to carry out this investigation directly in this last way, i.e. on suspensions of dry powder of alga Klamath in $\mathrm{D}_{2} \mathrm{O}$. The signals thus observed are due to molecules in solution, and the little suspended material does not affect negatively spectral resolution.

The water presaturated ${ }^{1} \mathrm{H}$ NMR spectrum of alga Klamath suspension is reported in Fig. 1. It is a very complex spectrum, dominated by the acetate signal at $1.93 \mathrm{ppm}$, then by signals within the carbohydrate region (5.5-3 ppm), the majority of which belong to high molecular weight species, that are in the negative NOE regime. ${ }^{28}$

Resonances due to aliphatic amino acids at low ppm are also clearly detected. Lower signals are found in the anomeric/ethylenic region and very low resonances in the aromatic one. An attempt to disentangle, at least partially, this heavily overlapped pattern was done through 2D homonuclear and heteronuclear spectra. COSY, TOCSY, NOESY, HSQC, HSQC-TOCSY and HMBC spectra were acquired, analysed and a number of metabolites was identified. The results are reported in Tables 1 and S1.

Some of the detected metabolites (alanine, Ala, and other aliphatic amino acids, acetate, Ac, lactate, Lac, aspartate, Asp, glutamate, Glu, glutamine, Gln, threonine, Thr, glucose, Glc, etc.) are quite common in natural matrixes and their signals can be readily interpreted and assigned. Nevertheless, in the case of alga Klamath a group of signals in the region 2.6 - 2.9 ppm, partially overlapped to those of $\mathrm{CH}_{2}-\beta$ of Asp (H/C correlations: 2.82,2.68/39.7), attracted our attention. These resonances are due to two $\mathrm{CH}_{2}$ with diastereotopic protons (H/C correlations: 2.89,2.74/36.1 ppm and 2.82,2.75/35.8 ppm, Fig. 2), that give two AB systems. They also give H,C long range correlations in HMBC spectrum (not shown) with carbons at 73.8, 128.0, 161.8 and $163.3 \mathrm{ppm}$, that allow to assembly the MAA skeleton (Scheme 1). This hypothesis 
was confirmed by other H,C long range and H,H NOE and ROE correlations (Fig. 3, Table 1), and allow to identify the presence of P334. P334 should be in its protonated form, for both $\mathrm{H}-11$ and $\mathrm{H}-8$ give correlations with NH protons in TOCSY experiment. These data compare well with those reported in the literature. ${ }^{18,29}$ Moreover, very close to P334 major signals, minor resonances were found at 2.92 and $2.77 \mathrm{ppm}$. They show clear ROESY cross peaks with protons at 4.34 and 3.57 ppm (Fig. 3). Signal at 4.34 derives from a methine proton $(\mathrm{C} 63.3 \mathrm{ppm})$ that correlates in COSY spectrum with methylene signals at 3.92 and $3.99 \mathrm{ppm}(\mathrm{C} 65.3$ ppm) and with carbons at 177.5 and $161.9 \mathrm{ppm}$ in the HSQC spectrum. This second set of minor signals was assigned to Shi, the other resonances of which overlap those of P334. Also in this case the spectral data parallel those reported in the literature for Shi methyl ester. ${ }^{30}$

Due to the high overlapping of P334 and Shi signals in the ${ }^{1} \mathrm{H}$ NMR spectrum, an estimate of the relative $\mathrm{P} 334 /$ Shi molar ratio of about 3:1 is better obtained, in the hypothesis of a very similar conformation, from the integrals of the cross peaks between $\mathrm{CH}_{2}-4$ and $\mathrm{CH}-11$ in the ROESY spectrum. Alternatively, in the hypothesis of similar ${ }^{1} \mathrm{~J}_{\mathrm{HC}}$ coupling values for the C,H-11 pair in both compounds, the P334/Shi molar ratio can be estimated by the HSQC C,H-11 correlations (at 4.06/67.3 ppm for P334 and at 4.34/63.3 ppm for Shi) as 2.3:1. However, in this case, the volume of $\mathrm{P} 334 \mathrm{C}, \mathrm{H}-11$ cross peak is underestimated, due to its proximity to a $\mathrm{CH}_{2}$ correlation of opposite sign.

The presence of both P334 and Shi was confirmed by ESI-MS and low-energy CID MS/MS spectra (see ESI-QTOF mass analysis section).

Figure 1 near here

Figure 2 near here

Figure 3 near here

$$
\text { Another group of interesting and intense correlations was distinguished in the HSQC carbohydrate region. }
$$
The most characteristic signals are the $\beta$-D-galactose doublet at $4.40 \mathrm{ppm}$ (bound to $\mathrm{C}$ at $105.8 \mathrm{ppm}$ that indicates the presence of a $\beta$-glycosidic linkage), and two methylene groups, with diastereotopic protons, and $\mathrm{H}, \mathrm{C}$ correlations that are found at 3.76,3.91/73.7 ppm and 3.60,3.66/65.3 ppm. Starting from 4.40 doublet, it is possible to derive a $\beta$-galactose spin system, through COSY and TOCSY correlations, up to $\mathrm{H}-4$ at 3.92 ppm, due to the low J coupling H-4,H-5 that lowers the efficiency of coherence transfer. Nevertheless, H-4 correlates with C-6, C-5, C-2 and C-3 in HMBC spectrum and these correlations permit to reconstruct the 
186

187

188

189

190

191

193

194

galactopyranosyl unit. Inter-residue ROE correlations between H-1 and 3.76,3.91 methylene signals allow GalpG (Fig. 2) to be recognized, and HSQC-TOCSY spectrum (Fig.S2a) confirms that 3.76,3.91 protons belong to the same spin system to which 3.60,3.66 protons belong, too. GalpG gives also rise to the highest signals in ${ }^{13} \mathrm{C}$ spectrum and its presence was confirmed by ESI-QTOF-MS results (see ESI-QTOF mass analysis section). This seems to us a quite peculiar finding, since $\alpha$-D-galactopyranosyl glycerols are usually found in algae ${ }^{31}$ and GalpG appears to be a glycoside that characterizes AFA metabolome.

A minor doublet at $4.43 \mathrm{ppm}$ (bound to $\mathrm{C}$ at $105.8 \mathrm{ppm}$ ) indicates the presence of another minor $\beta$-Dgalactoside, the spin system of which was only partially identified. Similarly, other low correlations due to glycosidic units were found (Table S1). The presence of GalpG, and similar water soluble molecules could be related to different types of glycoglycerolipids, ${ }^{32}$ that have significant anti-tumor activities towards different targets.

Two interesting spin systems were also highlighted by TOCSY (Fig. 4).

Figure 4 near here

The former recalls the spectral features of a 6-amino-6-deoxy- $\alpha$-D-glucopyranoside. The starting point is a methylene with diastereotopic protons at 3.07 and $3.38 \mathrm{ppm}(\mathrm{C}$ at $54.9 \mathrm{ppm})$, the correlations of which (in COSY, TOCSY and HSQC spectra) allow to gather a spin system formed by oxygenated methynes (H/C pairs: $4.05 / 70.93 .26 / 75.4,3.73 / 75.7,3.58 / 74.4$,) terminating with an $\alpha$-anomeric proton at $4.89 \mathrm{ppm}(\mathrm{C}$ at 101.1 ppm). The HSQC-TOCSY experiment (Fig.s S2b and S2d) confirms the assignments. The anomeric proton at $4.89 \mathrm{ppm}$ correlates, in the $\mathrm{HMBC}$ spectrum, with a carbon at $71.7 \mathrm{ppm}$, not belonging to the amino sugar ring, and gives ROE peaks with protons at $3.58 \mathrm{ppm}$ (its vicinal one) and 3.45, $3.94 \mathrm{ppm}$. These last two protons belong to a methylene group (the carbon of which resonates at $71.7 \mathrm{ppm}$, Fig. S3a) that gives HMBC correlations with carbons at 101.1 (bound to the proton resonating at $4.89 \mathrm{ppm}$ ), 73.6 (methyne) and $65.5 \mathrm{ppm}$ (methylene). No unambiguous one-bond proton-carbon correlation (in the HSQC spectrum) for carbons at 73.6 and $65.5 \mathrm{ppm}$. These findings point to a glyceryl 6-amino-6-deoxy- $\alpha$-Dglucopyranoside (ADG). The proton (shifted by $0.3-0.5 \mathrm{ppm}$ due to the different solvents employed) and carbon chemical shifts (within 0-3 ppm) parallel those reported for the 6-amino-6-deoxy ring of ishigoside, a glyceroglycolipid isolated from the Brown Alga Ishige okamurae, with radical scavenging properties. ${ }^{33}$ This seems to us another interesting finding, for it indicates the presence of glycerol 6-amino-6-deoxy glucosides in AFA. Nevertheless, we did not identify, through ESI-QTOF mass analysis, adducts related to ADG (see 
ESI-QTOF mass analysis section), hence we cannot exclude a further functionalization of this moiety at the amino group.

The second spin system is even more unusual and corresponds to DhLys. This spin system can be identified starting for instance from the doublet at $4.59 \mathrm{ppm}(\mathrm{C}$ at $54.7 \mathrm{ppm})$ which gives a COSY cross-peak with a triplet at $5.66 \mathrm{ppm}$ and TOCSY cross peaks with protons at 5.88, 5.66, 2.58, 2.66, 3.13 and $3.19 \mathrm{ppm}$. The last four belong to methylenes group, the carbons of which are found at 28.2 and $41.4 \mathrm{ppm}$, respectively. The presence of a double bond on the backbone of the fragment is confirmed by the chemical shifts of carbons bound to 5.66 and $5.88 \mathrm{ppm}$ protons (128.1 and $135.1 \mathrm{ppm}$, respectively) and the cis- configuration of the double bond is derived by the coupling constant (about $10 \mathrm{~Hz}$ ) between the two ethylenic protons, and a clear ROE between $4.59 \mathrm{ppm}$ and 2.58, $2.66 \mathrm{ppm}$ signals. This spectral picture is confirmed by HSQCTOCSY correlations (Fig. S3c). No inter-residue ROEs were detected for DhLys and, in this case, a mass peak corresponding to the protonated molecule $[\mathrm{M}+\mathrm{H}]^{+}$was found in ESI-QTOF spectra, confirming the presence of this molecule. Nevertheless, DhLys appears to be quite puzzling, for usually trans-3,4-DhLys moiety is found in important anticancer bioactive compounds, such as syringolin A (SylA). Syl A has been identified as a virulence factor, which irreversibly inhibits the $20 \mathrm{~S}$ proteasome through a covalent mechanism. ${ }^{34}$ Proteasome inhibitors, such as the clinically-used anticancer agent bortezomib, represent a powerful class of chemotherapeutics. ${ }^{35}$ Syls are a family (Syl A-F) of natural products formed by twelvemembered macrolactams produced by strains of Pseudomonas syringae. The targeted search of protonated molecule or other adducts of Syls A, D and F (those containing trans-DhLys) within ESI-QTOF mass spectral data did not give any result. Hence, we cannot derive a correlation between the presence of cis-3,4DhLys and Syls in AFA.

A final comment is deserved to the aromatic region of the proton spectrum (Fig. 1), characterized by resonances mainly due to nucleobase derivatives (Table S1). Signals from alkylsubstituted phenyl rings were found, as confirmed by the HSQC experiment, that displays correlations between proton $(7.4 \div 7.2 \mathrm{ppm})$ and carbon $(133 \div 130 \mathrm{ppm})$ signals. Nevertheless, we cannot relate these resonances to free phenylethylamine, because its aliphatic signals were not clearly detected.

High performance liquid chromatography ESI-QTOF-MS was employed, operating both in positive and negative ionization mode, to confirm the presence of the metabolites detected through NMR analysis. The ESI-QTOF-MS (positive ion mode) gave a very complex total ion current chromatogram. The metabolites 
244

245

246

247

GalpG, Shi and P334 eluted within the first two minutes and gave the highest contribution to the total ion current to peaks at 1.5, 1.8 and $2.0 \mathrm{~min}$. DhLys peak co-eluted with other ions at $1.3 \mathrm{~min}$. DhLys, P334 and Shi were detected as the protonated molecule $[\mathrm{M}+\mathrm{H}]^{+}$, whereas GalpG was detected as a mixture of the protonated molecule $[\mathrm{M}+\mathrm{H}]^{+}$and ammonium adduct $\left[\mathrm{M}+\mathrm{NH}_{4}\right]^{+}$.

In addition, in ESI-QTOF-MS negative ion mode experiments the metabolites were detected as $[\mathrm{M}-\mathrm{H}]^{-}$ions, whereas GalpG was also detected as formiate adduct [M+HCOO] ${ }^{-}$at $\mathrm{m} / \mathrm{z} 299$.

Low-energy CID MS/MS spectra of Shi and P334 (Fig. S4) parallel those reported by other authors, ${ }^{36}$ whereas GalpG CID spectrum in negative mode (Fig. S5) is similar to that reported for its $\alpha$ isomer by Chen et al.. ${ }^{37}$ The formulae that best fit the experimental isotopic peak intensity ratios of molecular species were $\mathrm{C}_{14} \mathrm{H}_{22} \mathrm{~N}_{2} \mathrm{O}_{8}$ and $\mathrm{C}_{13} \mathrm{H}_{20} \mathrm{~N}_{2} \mathrm{O}_{8}$ for $\mathrm{P} 334$ and Shi, respectively.

In the case of GalpG, the isotopic cluster of the protonated molecule and of the ammonium adduct suffer from peak overlapping with other species in all the MS spectra acquired. Hence, we checked the isotopic peak intensity ratio of the product ion $[\mathrm{M}-\mathrm{H}]^{-}$cluster at $\mathrm{m} / \mathrm{z} 253$, obtained from the product ion scan of the formiate adduct $[\mathrm{M}+\mathrm{HCOO}]^{-}$at $\mathrm{m} / \mathrm{z} 299$. The formula that best fits experimental intensities is $\mathrm{C}_{9} \mathrm{H}_{18} \mathrm{O}_{8}$. We were not able to check the isotopic cluster intensities of m/z 145 DhLys peak, for it suffers from severe overlapping in all MS spectra and we did not find other molecular species other than $[\mathrm{M}+\mathrm{H}]^{+}$and $[\mathrm{M}-\mathrm{H}]^{-}$ (Fig. S6).

As for ADG, we did not come to an unambiguous structural assignment through MS/MS spectra. We searched the product ion scans for neutral losses of amino sugars $(\mathrm{m} / \mathrm{z} 179)$ or of their dehydrated forms $(\mathrm{m} / \mathrm{z}$ 161) and for product ions corresponding to protonated amino sugars ( $\mathrm{m} / \mathrm{z} 180)$ or protonated dehydrated amino sugars (m/z 162). A possible species containing the 6-amino-6-deoxy- $\alpha$-D-glucopyranosyl fragment could be the $\mathrm{m} / \mathrm{z} 455$ ion (Fig. S7) that displays a m/z 179 neutral loss and shows product ions at $\mathrm{m} / \mathrm{z} 162$ and 180. The remaining ions, in particular those at $\mathrm{m} / \mathrm{z} 84,126,138,144,168,186$ and 276 , are the same reported for the fragmentation of $N$-acetyl muramic acid. Our data suggest that $\mathrm{m} / \mathrm{z} 455$ ion could derive from $\mathrm{N}$-acetyl muramic acid, or an isomer of it, bound to an amino sugar. $\mathrm{N}$-acetyl muramic acid is usually bound to $N$-acetyl glucosamine in bacterial cells, and it has been reported that cell walls of blue-green algae possess a mucopolymer similar to that of bacterial cell walls. ${ }^{38}$ Thus, we hypothesize that ADG could be involved in the structure of such a mucopolymer. 

suspensions reveals a very complex metabolic profile. Resonances from small metabolites, overlapped to a background due to signals coming from high molecular weight polysaccharides, were detected. Apart from free and bound amino acids and monosaccharides, the most interesting metabolites found are two MAAs, i.e. P334 and Shi, two glycopyranosides, i.e. GalpG, and ADG, and cis-3,4-DhLys. All these molecules possess known nutraceutical properties and high biological activity. The presence of cis-3,4-DhLys was revealed for the first time, even though we were not able to find a direct connection to Syls production.

NMR findings were checked by ESI-QTOF-MS that confirmed most of them, leaving the complete structure of the ADG-derivative still an open question.

Although this study proves the value of the application of NMR spectroscopy directly on complex mixtures and it supports the use of NMR to monitor valuable metabolites, such as P334 and Shi, directly of AFA powder suspensions, further investigations are necessary to gain a deeper insight into the very complex AFA metabolome. 
286

287

288

289

290

291

292

293

294

295

296

297

298

299

300

301

302

303

304

305

306

\section{ABBREVIATIONS}

Ac, acetate; ADG, glyceryl 6-amino-6-deoxy- $\alpha$-D-glucopyranoside; AFA, Aphanizomenon flos-aquae; Ala, alanine; Asp, aspartate; CID MS/MS, low-energy Collision-Induced Dissociation tandem mass spectrometry; COSY, COrrelation Spectroscopy; DhLys, dehydrolysine; ESI, Electrospray Ionization; GalpG, glyceryl $\beta$-Dgalactopyranoside; Glc, glucose; Gln, glutamine; Glu, glutamate; HMBC, Heteronuclear Multiple Bond Correlation; HR-MAS, High Resolution Magic Angle Spinning; HSQC, Heteronuclear Single Quantum Coherence; Lac, lactate; MAAs, mycosporine-like amino acids; MAO, monoamine oxidase; MS, mass spectrometry; NMR, Nuclear Magnetic Resonance; NOESY, Nuclear Overhauser Effect SpectroscopY; P334, porphyra-334; QTOF, Quadrupole-Time-of-Flight; ROESY, Rotating Overhauser Effect SpectroscopY; Shi, shinorine; Syl, syringolin; Thr, threonine; TOCSY, TOtal Correlation Spectroscopy.

\section{ACKNOWLEDGEMENTS}

Fondazione Cassa di Risparmio di Modena and Centro Interdipartimentale Grandi Strumenti of the University of Modena and Reggio Emilia are greatly acknowledged for financial support in the acquisition of the Bruker Avance III HD 600 Spectrometer.

\section{SUPPORTING INFORMATION}

SI contains Figures reporting selected regions of HSQC-TOCSY, HSQC spectra, low-energy CID MS/MS spectra and a Table with further NMR data for metabolites found in AFA. 


\section{REFERENCES}

308

309

310

(1) Baroni, L.; Scoglio, S.; Benedetti, S.; Bonetto, C.; Pagliarani, S.; Benedetti, Y.; Rocchi, M.; Canestrari, F. Effect of a Klamath algae product ("AFA-B12") on blood levels of vitamin B12 and homocysteine in vegan subjects: a pilot study. Int. J. Vitam. Nutr. Res. 2009, 79, 117-123.

(2) Hart, A. N.; Zaske, L. A.; Patterson, K. M.; Drapeau, C.; Jensen G. S. Natural killer cell activation and modulation of chemokine receptor profile in vitro by an extract from the cyanophyta Aphanizomenon flos-aquae. J. Med. Food 2007, 10, 435-441.

(3) Pugh, N.; Pasco, D.S. Characterization of human monocyte activation by a hydrosoluble preparation of Aphanizomenon flos-aquae. Phytomedicine 2001, 8, 445-453.

(4) Scoglio, S.; Benedetti, S.; Canino, C.; Santagni, S.; Rattighieri, E.; Chierchia, E.; Canestrari, F.; Genazzani, D. A. Effect of a 2-month treatment with Klamin ${ }$, a Klamath algae extract, on the general well-being, antioxidant profile and oxidative status of postmenopausal women. Gynecol. Endocr. 2009, $25,235-240$.

(5) Scoglio, S.; Benedetti, Y.; Benvenuti, F.; Battistelli, S.; Canestrari, F.; Benedetti, S. Selective monoamine oxidase B inhibition by an Aphanizomenonflos-aquae extract and by its constitutive active principles phycocyanin and mycosporine-like amino acids. Phytomedicine 2014, 21, 992-997.

(6) Benedetti, S.; Benvenuti F.; Pagliarani S.; Francogli S.; Scoglio, S.; Canestrari, F. Antioxidant properties of a novel phycocyanin extract from the blue-green alga Aphanizomenon flos-aquae. Life Sci. 2004, 75, $2353-2362$.

(7) Benedetti, S.; Benvenuti, F.; Scoglio, S.; Canestrari, F. Oxygen radical absorbance capacity of phycocyanin and phycocyanobilin from the food supplement Aphanizomenon flos-aquae. J. Med. Food 2010, 13, 223-227.

(8) Gilroy, D. J.; Kauffman, K. W.; Hall, R. A.; Huang, X.; Chu F. S. Assessing potential health risks from microcystin toxins in blue-green algae dietary supplements. Environ. Health Persp. 2000, 108, 435-439.

(9) Kusaga, A. Decreased beta-phenylethylamine in urine of children with attention deficit hyperactivity disorder and autistic disorder. No To Hattatsu 2002, 34, 243-248.

(10) Kusaga, A.; Yamashita, Y.; Koeda, T.; Hiratani, M.; Kaneko, M.; Yamada, S.; Matsuishi, T. Increased urine phenylethylamine after methylphenidate treatment in children with ADHD. Ann. Neurol. 2002, 52, $372-374$. 
336

337

338

339

340

(11) Sedriep, S.; Xia, X.; Marotta, F.; Zhou, L.; Yadav, H.; Yang, H.; Soresi, V.; Catanzaro, R.; Zhong, K.; Polimeni, A.; Chui, D. H. Beneficial nutraceutical modulation of cerebral erythropoietin expression and oxidative stress: an experimental study. J. Biol. Reg. Homeos. Ag. 2011, 25, 187-194.

(12) Shytle, D. R.; Tan, J.; Ehrhart, J.; Smith, A. J.; Sanberg, C. D.; Sanberg, P. R.; Anderson, J.; Bickford, P. C. Effects of blue-green algae extracts on the proliferation of human adult stem cells in vitro: a preliminary study. Med. Sci. Monit. 2010, 16, 1-5.

(13) Bhat, V. B.; Madyastha, K. M. C-phycocyanin: a potent peroxyl radical scavenger in vivo and in vitro. Biochem. Bioph. Res. Commun. 2000, 275, 20-25.

(14) Bhat, V. B.; Madyastha, K. M. Scavenging of peroxynitrite by phycocyanin and phycocyanobilin from Spirulina platensis: protection against oxidative damage to DNA. Biochem. Bioph. Res. Commun. 2001, 285, 262-266.

(15) Romay, C.; Gonzalez, R. Phycocyanin is an antioxidant protector of human erythrocytes against lysis by peroxyl radicals. J. Pharm. Pharmacol. 2000, 52, 367-368.

(16) Romay, C.; Armesto, J.; Remirez, D.; Gonzalez, R.; Ledon, N.; Garcia, I. Antioxidant and antiinflammatory properties of C-phycocyanin from blue-green algae. Inflamm. Res. 1998, 47, 36-41.

(17) Reddy, C.M.; Bhat, V.B.; Kiranmai, G.; Reddy, M.N.; Reddanna, P.; Madyastha, K.M. Selective inhibition of cyclooxygenase-2 by C-phycocyanin, a biliprotein from Spirulina platensis. Biochem. Bioph. Res. Commun. 2000, 277, 599-603.

(18) Torres, A.; Enk, C. D.; Hochberg, M.; Srebnik, M. Porphyra-334, a potential natural source for UVA protective sunscreens. Photochem. Photobiol. Sci. 2006, 5, 432-435.

(19) Scoglio, S.; Canestrari, F.; Benedetti, S.; Benedetti, Y.; Delgado-Esteban, M. Aphanizomenon flos aquae preparation, extracts and purified components thereof for the treatment of neurological, neurodegenerative and mood disorders. WO 2008000430 2008, A2.

(20) Choi, Y-H.; Yang, D. J.; Kulkarni, A.; Moh, S. H.; Kim. K. W. Mycosporine-Like Amino Acids Promote Wound Healing through Focal Adhesion Kinase (FAK) and Mitogen-Activated Protein Kinases (MAP Kinases) Signaling Pathway in Keratinocytes. Mar. Drugs 2015, 13, 7055-7066.

(21) Abd El-Baky, H. H.; El Baz, F. K.; El-Baroty G. S. Characterization of nutraceutical compounds in blue green alga Spirulina maxima. J. Med. Plants Res. 2008, 2, 292-300. 
364

365

366

367

368

369

370

371

372

373

374

375

376

377

378

379

380

381

382

383

384

385

386

387

388

389

390

(22) Benedetti, S.; Rinalducci, S.; Benvenuti, F.; Francogli, S.; Pagliarani, S.; Giorgi, L.; Micheloni, M.; D’Amici, G.M.; Zolla, L.; Canestrari, F. Purification and characterization of phycocyanin from the bluegreen alga Aphanizomenon flos-aquae. J. Chromatogr. B: Anal. Technol. Biomed. Life Sci. 2006, 833, 12-18.

(23) Evans, A. M.; Li, D.; Jones, A.; Games, M. P.; Games, D. E.; Gallon, J. R.; Walton, T. J. Analysis by gas chromatography-mass spectrometry of the fatty acid composition during temperature adaptation in Aphanizomenon flos-aquae, a diazotrophic cyanobacterium from the Baltic Sea. Biochem. Soc. Trans. 1996, 24, 475S.

(24) Abd El-Bakya, H. H.; El-Baroty, G. S. Characterization and bioactivity of phycocyanin isolated from Spirulina maxima grown under salt stress Food Function 2012, 3, 381-388.

(25) Mendiola, J. A.; Marn, F R.; Hernndez, F. S.; Arredondo O. B.; Seorns F. J.; Ibaez, E.; Reglero, G. Characterization via liquid chromatography coupled to diode array detector and tandem mass spectrometry of supercritical fluid antioxidant extracts of Spirulina platensis microalga. J. Sep. Sci. 2005, 28, 1031-1038.

(26) Mucci, A.; Parenti, F.; Righi, V.; Schenetti, L. Citron and Lemon under the lens of HR-MAS NMR spectroscopy. Food Chem. 2013, 141, 3167-3176.

(27) Righi, V.; Parenti, F.; Tugnoli, V.; Schenetti, L.; Mucci, A. Crocus sativus Petals: Waste or Valuable Resource? The Answer of High-Resolution and High-Resolution Magic Angle Spinning Nuclear Magnetic Resonance. J. Agric. Food Chem. 2015, 63, 8439-8444.

(28) Neuhaus, D.; Williamson, M.P. The Nuclear Overhauser Effect in Structural and Conformational Analysis. 2nd Edition, Wiley-VCH: New York, 2000.

(29) Klisch, M.; Richter, P.; Puchta, R.; Donat-P. Häder, D-P.; Bauer, W. The Stereostructure of Porphyra334: An Experimental and Calculational NMR Investigation. Evidence for an Efficient 'Proton Sponge'. Helv. Chim. Acta 2007, 90, 488-511.

(30) Carignan, M. O.; Carreto, J. I. Characterization Of Mycosporine-Serine-Glycine Methyl Ester, A Major Mycosporine-Like Amino Acid From Dinoflagellates: A Mass Spectrometry Study. J. Phycol. 2013, 49, 680-688. 
391

392

393

394

395

396

397

398

399

400

401

402

403

404

405

406

407

408

409

410

411

412

413

414

415

(31) Broberg, A.; Kenne, L. Use of High-Resolution Magic Angle Spinning Nuclear Magnetic Resonance Spectroscopy for in Situ Studies of Low-Molecular-Mass Compounds in Red Algae. Anal. Biochem. 2000, 284, 367-374.

(32) Zhang, J.; Li, C.; Yu, G.; Guan, H. Total Synthesis and Structure-Activity Relationship of Glycoglycerolipids from Marine Organisms. Mar. Drugs 2014, 12, 3634-3659.

(33) Zou, Y.; Li, Y.; Kim, M-M.; Lee, S-H.; Kim, S-H. Ishigoside, a New Glyceroglycolipid Isolated from the Brown Alga Ishige okamurae. Biotechnol. Bioprocess Eng. 2009, 14, 20-26.

(34) Groll, M.; Schellenberg, B.; Bachmann, A. S.; Archer, C. R.; Huber, R.; Powell, T. K.; Lindow, S.; Kaiser, M.; Dudler, R. A plant pathogen virulence factor inhibits the eukaryotic proteasome by a novel mechanism. Nature 2008, 452, 755-758.

(35) Groll, M.; Berkers, C. R.; Ploegh, H. L.; Ovaa, H. Crystal structure of the boronic acid-based proteasome inhibitor bortezomib in complex with the yeast 20S proteasome. Structure 2006, 14, 451456.

(36) Roullier, C.; Chollet-Krugler, M.; Pferschy-Wenzig, E-M.; Maillard, A.; Rechberger, G. N.; LegouinGargadennec, B.; Bauer, R.; Boustie, J. Characterization and identification of mycosporines-like compounds in cyanolichens. Isolation of mycosporine hydroxyglutamicol from Nephroma laevigatum Ach. Phytochem. 2011, 72, 1348-1357.

(37) Chen, J.; Song, D.; Luo, Q.; Mou, T.; Yang, R.; Chen, H.; He, S.; Yan X. Determination of Floridoside and Isofloridoside in Red Algae by High-Performance Liquid Chromatography Tandem Mass Spectrometry, Anal. Lett. 2014, 47, 2307-2316.

(38) Drews, G.; Meyer, H. Chemical composition of cell walls of Anacystis nidulans and Chlorogloea fritschii. Arch. Microbiol. 1964, 48, 259-267.

16 


\section{FIGURE CAPTIONS}

417

418 Scheme 1. Structures of porphyra-334 (P334), shinorine (Shi), glyceryl $\beta$-D-galactopyranoside (GalpG), cis419 3,4-dehydrolysine (DhLys) and glyceryl 6-amino-6-deoxy- $\alpha$-D-glucopyranoside (ADG).

420 Fig. 1. Water-presaturated ${ }^{1} \mathrm{H}$ NMR spectrum of Klamath algae suspension in $\mathrm{D}_{2} \mathrm{O}$.* residual HDO signal. 421 Interesting metabolites are labelled: porphyra-334 (P334), shinorine (Shi), glyceryl $\beta$-D-galactopyranoside 422 (GalpG), cis-3,4-dehydrolysine (DhLys), glyceryl 6-amino-6-deoxy- $\alpha$-D-glucopyranoside (ADG), alanine 423 and bound forms of alanine (Ala, Ala- and -Ala), acetate (Ac), $N$-acetyls ( $N$-Ac), lactate (Lac), aspartate 424 (Asp), threonine (Thr).

425 Fig. 2. Partial HSQC spectrum of Klamath algae suspension in $\mathrm{D}_{2} \mathrm{O}$ evidencing signals of $\mathrm{P} 334$, Shi (ovals) 426 and GalpG (rectangles).

427 Fig. 3. Partial ROESY spectrum of Klamath algae suspension in $\mathrm{D}_{2} \mathrm{O}$ evidencing signals of $\mathrm{P} 334$ and Shi.

428 Fig. 4. Partial TOCSY spectrum of Klamath algae suspension in $\mathrm{D}_{2} \mathrm{O}$ evidencing signals of DhLys 429 (left) and ADG (right)

430 
Table 1. NMR data $\left(600 \mathrm{MHz}, \mathrm{D}_{2} \mathrm{O}\right)$ for selected metabolites found in $\mathrm{AFA}^{\mathrm{a}}$

\begin{tabular}{|c|c|c|c|c|}
\hline Metabolite & nuclei & $\mathrm{H}(\delta, \mathrm{ppm}, \mathrm{J}, \mathrm{Hz})$ & $\mathrm{C}(\delta, \mathrm{ppm})$ & Note $^{b}$ \\
\hline \multirow[t]{8}{*}{ P334 } & $\mathrm{CH}_{2}-8$ & 4.03 & 49.5 & $\begin{array}{l}\text { HMBC } 163.3(\mathrm{C} 1), 177.7(\mathrm{C} 9) \text {, } \\
\text { COSY, TOCSY } 8.6(\mathrm{NH})\end{array}$ \\
\hline & $\mathrm{CH}_{2}-6$ & $\begin{array}{l}2.75(\mathrm{~d}, \mathrm{~J}=17.3), 2.82 \\
(\mathrm{~d}, \mathrm{~J}=17.3)\end{array}$ & 35.8 & $\begin{array}{l}\text { HMBC } 163.3(\mathrm{C} 1) \\
\text { ROESY } 4.03\end{array}$ \\
\hline & $\mathrm{CH}_{2}-7$ & 3.57 & 70.4 & HMBC 35.8, 36.1, 73.8 (C5) \\
\hline & $\mathrm{CH}_{2}-4$ & $\begin{array}{l}2.89(\mathrm{~d}, \mathrm{~J}=17.3), 2.74 \\
(\mathrm{~d}, \mathrm{~J}=17.3)\end{array}$ & 36.1 & $\begin{array}{l}\text { HMBC } 161.8(\mathrm{C} 3), 73.8(\mathrm{C} 5) \\
128.5(\mathrm{C} 2) \\
\text { ROESY with } 4.06\end{array}$ \\
\hline & $\mathrm{CH}_{3}-10$ & 3.69 & 62.2 & HMBC $128.5(\mathrm{C} 2)$ \\
\hline & CH-11 & 4.06 & 67.3 & $\begin{array}{l}\text { HMBC } 178.2(\mathrm{C} 14), 161.8 \\
(\mathrm{C} 3), \text { TOCSY } 7.63(\mathrm{NH})\end{array}$ \\
\hline & $\mathrm{CH}_{3}-13$ & $1.25(\mathrm{~d}, 6.3)$ & 22.2 & $\begin{array}{l}\text { HMBC } 67.3,71.0 \\
\text { NOESY } 2.89 \\
\text { TOCSY } 7.63(\mathrm{NH})\end{array}$ \\
\hline & $\mathrm{CH}-12$ & 4.30 & 71.0 & $\operatorname{COSY} 1.25,4.06$ \\
\hline \multirow[t]{3}{*}{ Shi serine residue } & $\mathrm{CH}_{2}-4$ & $\begin{array}{l}2.92(\mathrm{~d}, \mathrm{~J}=17.2), 2.77 \\
(\mathrm{~d}, \mathrm{~J}=17.2)\end{array}$ & 36.1 & ROESY $3.57,4.34$ \\
\hline & $\mathrm{CH}-11$ & 4.34 & 63.3 & $\begin{array}{l}\text { HMBC } 177.5(\mathrm{C} 13), 161.9 \\
\text { (C3) } \\
\text { COSY 3.92, } 3.99\end{array}$ \\
\hline & $\mathrm{CH}_{2}-12$ & $3.92(\mathrm{t}), 3.99(\mathrm{~d})$ & 65.3 & HMBC 177.5 (C13) \\
\hline \multirow[t]{9}{*}{ GalpG } & $\mathrm{CH}-1$ & $\begin{array}{l}4.40(\mathrm{~d}, \\
\mathrm{J}=8 \mathrm{~Hz})\end{array}$ & 105.9 & $\begin{array}{l}\text { ROESY } 3.54,3.65,3.683 .76 \text {, } \\
3.91\end{array}$ \\
\hline & $\mathrm{CH}-2$ & 3.55 & 73.7 & HMBC $105.9,75.5$ \\
\hline & $\mathrm{CH}-3$ & 3.65 & 75.5 & HMBC 73.6 \\
\hline & $\mathrm{CH}-4$ & 3.92 & 71.5 & HMBC 78.0, 73.6, 75.5, 63.8 \\
\hline & $\mathrm{CH}-5$ & 3.69 & 78.0 & НМBC $63.8,71.5$ \\
\hline & $\mathrm{CH}_{2}-6$ & $3.76,3.79$ & 63.8 & HMBC 78.0 \\
\hline & $\mathrm{CH}_{2}-1^{\prime}$ & $3.76,3.91$ & 73.7 & HMBC 105.9, 65.3 \\
\hline & $\mathrm{CH}-2^{\prime}$ & 3.93 & 73.2 & HMBC 73.7 \\
\hline & $\mathrm{CH}_{2}-3^{\prime}$ & $3.60,3.66$ & 65.3 & HMBC 73.7 \\
\hline $\mathrm{ADG}$ & $\mathrm{CH}-1$ & $4.89(\mathrm{~d}, 3.6)$ & 101.1 & $\begin{array}{l}\text { HMBC: } 70.9,71.7,75.9 \\
\text { COSY } 3.58, \\
\text { TOCSY } 3.07,3.38,3.26,3.58 \text {, } \\
3.75,4.06 \\
\text { ROESY } 3.45,3.58 .\end{array}$ \\
\hline
\end{tabular}




\begin{tabular}{llll}
$\mathrm{CH}-2$ & 3.58 & 74.4 & \\
$\mathrm{CH}-3$ & $3.73(\mathrm{t})$ & 75.7 & \\
$\mathrm{CH}-4$ & $3.26(\mathrm{t}, 13)$ & 75.4 & HMBC 54.9, 70.9, 75.7 \\
$\mathrm{CH}-5$ & $4.05(\mathrm{t}, 10)$ & 70.9 & \\
$\mathrm{NCH}_{2}-$ & $3.07(\mathrm{dd}, 9.7,14.7), 3.38$ & 54.9 & HMBC 70.9, 75.4 \\
6 & $(\mathrm{t}, 14.7)$ & & \\
$\mathrm{CH}_{2}-1^{\prime}$ & $3.45(\mathrm{t}), 3.94(\mathrm{~d})$ & 71.7 & HMBC 65.5, 73.6, 101.1 \\
& & & TOCSY 3.69, 3.59, 3.94 \\
& & 73.6 & \\
$\mathrm{CH}-2^{\prime}$ & $\mathrm{nd}$ & 65.5 & \\
$\mathrm{CH}{ }^{-} 3^{\prime}$ & $3.69,3.59$ & & \\
& & 54.7 & HMBC 128.1, 135.1, 175.6 \\
$\mathrm{CH}-2$ & $4.59(\mathrm{~d}, 9.8 \mathrm{~Hz})$ & & ROESY 2.66, 2.58 \\
& & 128.1 & \\
$\mathrm{CH}-3$ & $5.66(\mathrm{t}, 10.2 \mathrm{~Hz})$ & 135.1 & \\
$\mathrm{CH}-4$ & $5.88(\mathrm{~m})$ & 28.2 & HMBC 135.1, 128.1, 41.3 \\
$\mathrm{CH}{ }_{2}-5$ & $2.58,2.66$ & 41.3 & HMBC 135.1, 28.2 \\
\hline $\mathrm{CH}{ }_{2}-6$ & $3.13,3.19$ & & \\
\hline
\end{tabular}

$432{ }^{a}$ Ala $\mathrm{CH}_{3}$ signal (at 1.47 and 19.0 ppm, for proton and carbon, respectively, see Table S1) was used as internal reference for ${ }^{1} \mathrm{H}$ and ${ }^{13} \mathrm{C}$ chemical shifts.

434

${ }^{\mathrm{b}}$ Relevant correlations observed in 2D spectra: HMBC, TOCSY, COSY, ROESY, NOESY. 
<smiles>COC1=C(NCC(=O)O)CC(O)(CO)C/C1=N\[C@@H](C(=O)O)C(C)O</smiles>

P334<smiles>CNC1=C(OC)C(=N[C@@H](CO)C(=O)O)CC(O)(CO)C1</smiles>

Shi



GalpG

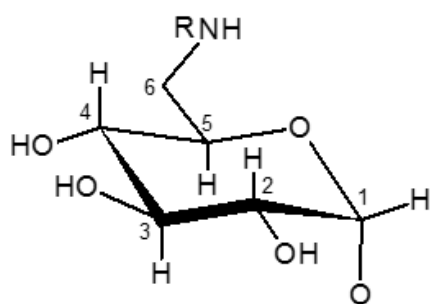

ADG<smiles>NCC/C=C\C(N)C(=O)O</smiles>

Dhlys

Scheme 1 

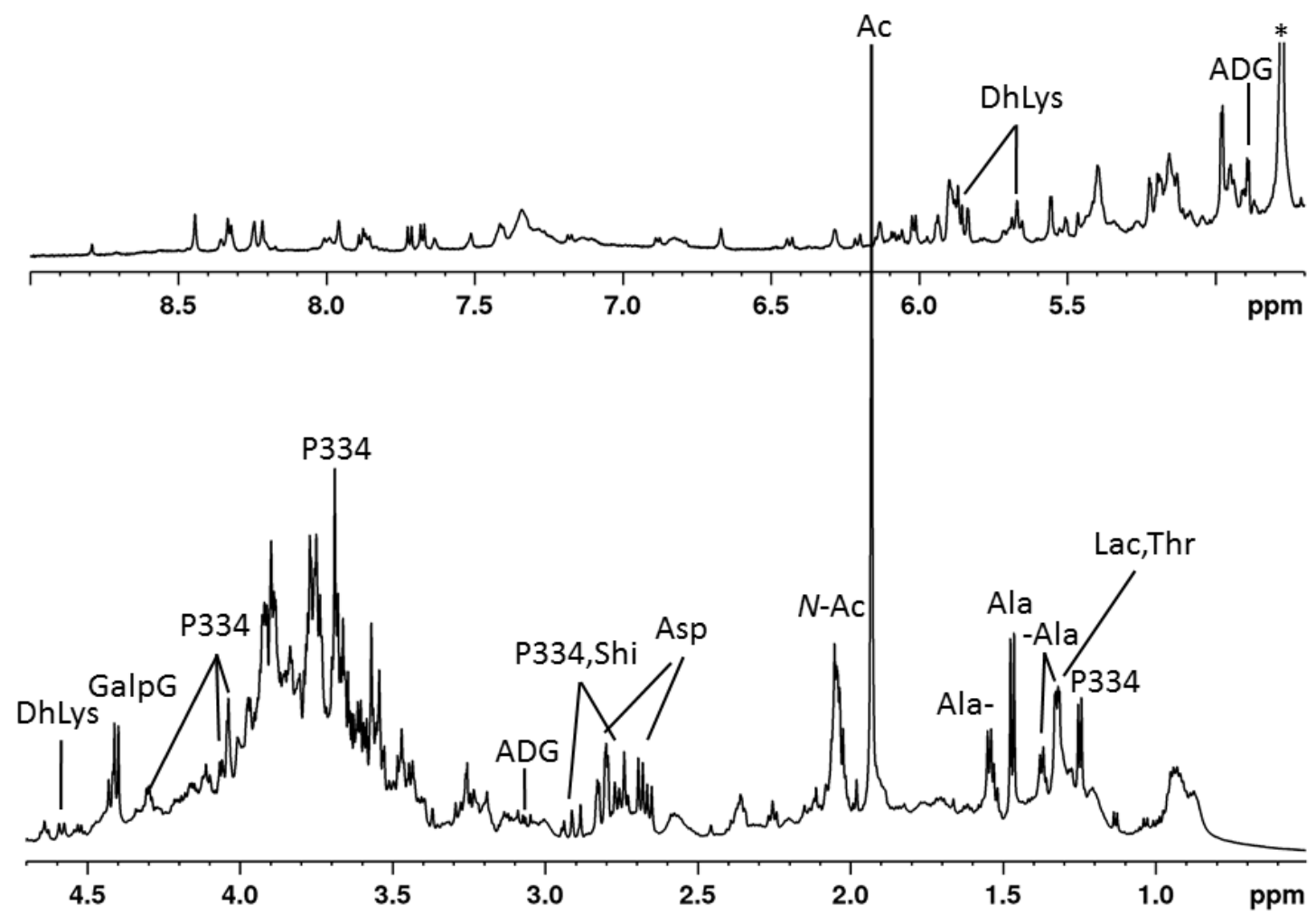

Figure 1 


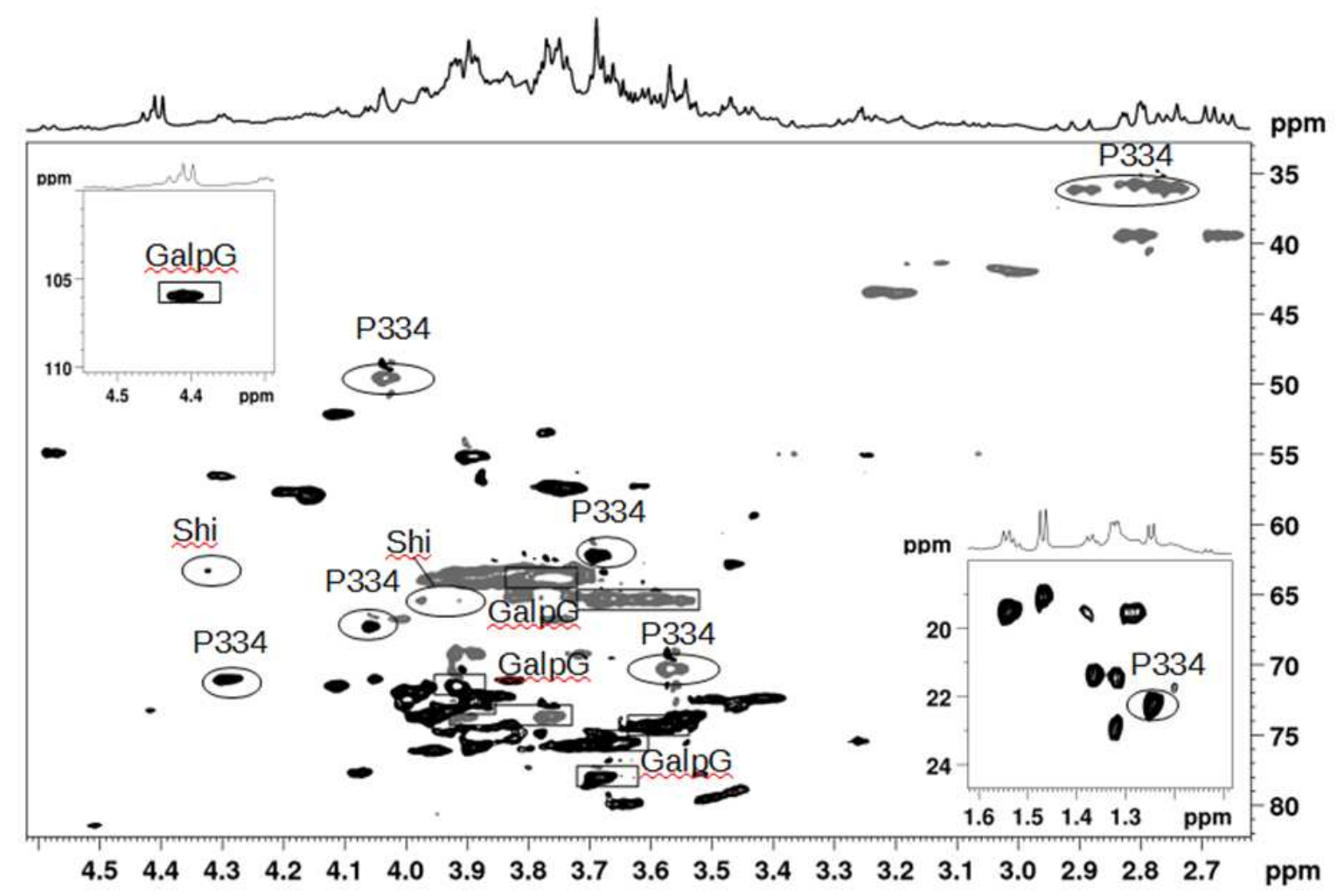

440

441

Figure 2 


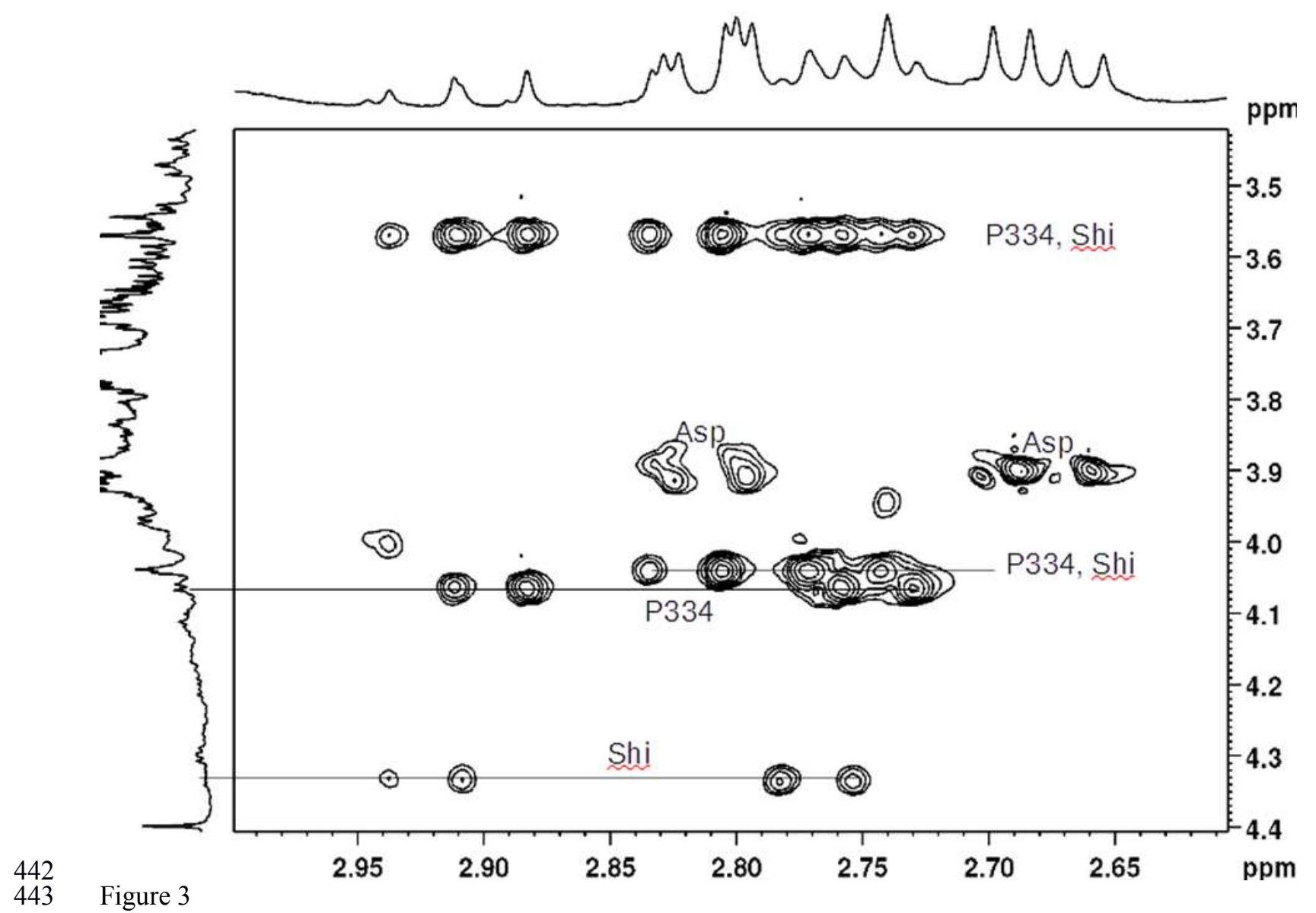




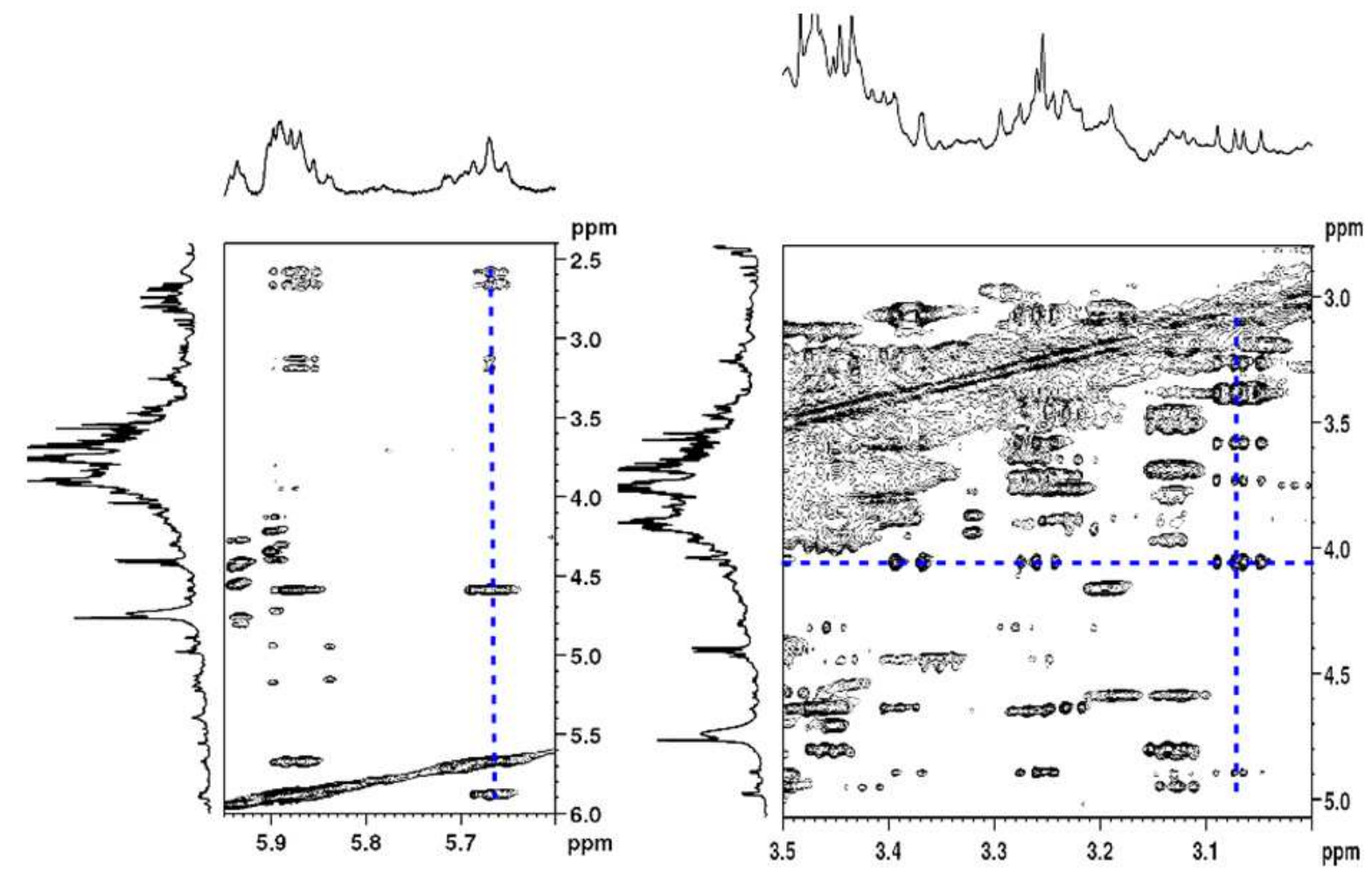

444

445

446

Figure 4 
447

448

449

450

\section{GRAPHIC FOR TOC}

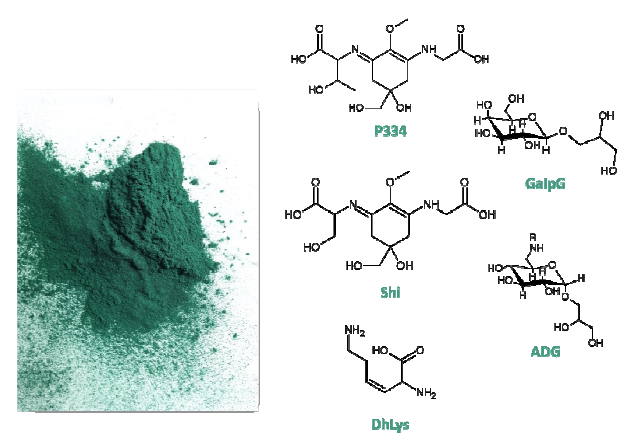

